\title{
Books on biodiversity and conservation
}

\author{
David L. Hawksworth ${ }^{1,2,3}$
}

Received: 20 September 2020 / Accepted: 22 September 2020/Published online: 10 October 2020

(C) Springer Nature B.V. 2020

\begin{abstract}
Reviews and notices are provided on 23 books, published over the years 2017-2020. These are concerned with diverse aspects of biodiversity and conservation, including historical works on different types of institutions, climate change and palaeobiology, global health and sustainability, ecology, restoration, community involvement, animal behaviour, utilization, and regional studies. This is the eighth of a series of cumulative book reviews and notices, based on works submitted by the publishers, which generally appear annually in the journal.
\end{abstract}

Keywords Climate change $\cdot$ Conservation $\cdot$ Biodiversity $\cdot$ Ecology $\cdot$ Field biology $\cdot$ Marine biology $\cdot$ Palaeoecology $\cdot$ Sustainability $\cdot$ Zoos

\section{Introduction}

As for other compilations provided periodically in Biodiversity and Conservation since 2011, the present contribution features titles received from their publishers. The aim is to issue one such instalment each year, depending on space constraints. This is the eighth, and the previous one appeared in 2018 (Biodiversity and Conservation 27: 3561-3572).

This instalment covers 23 books published in the period 2017-20, and concerned with diverse aspects of biodiversity and conservation, including historical works on different types of institutions, climate change and palaeobiology, global health and sustainability, ecology, restoration, community involvement, animal behaviour, utilization, and regional studies as well as some dealing with particular regions.

Publishers wishing to have their titles considered for inclusion in the series are requested to send hard copies (not e-books) to me, as Editor-in-Chief, at Milford House, 10 The Mead, Ashtead, Surrey KT21 2LZ, UK; e-books. All reviews presented here are to be

Communicated by David Hawksworth.

David L. Hawksworth

d.hawksworth@nhm.ac.uk

1 Department of Life Sciences, The Natural History Museum, Cromwell Road, London SW7 5BD, UK

2 Comparative Plant and Fungal Biology, Royal Botanic Gardens, Kew TW9 3DS, Surrey, UK

3 Jilin Agricultural University, Changchun 130118, Jilin Province, China 
attributed to me, unless otherwise indicated, and in addition we are always pleased to receive reviews prepared by others for consideration for inclusion.

\section{Historical perspectives}

\section{Science, conservation, and national parks}

Edited by Steven R. Beissinger, David D. Ackerly, Holly Doremus, and Gary E. Machlis University of Chicago Press, Chicago, USA, 2017, 416 pp. 51 illustr., 13 tables. ISBN 978-0-226-42300-5 (pbk), Price: US\$ 45.

This is a testament to what can be achieved by determined conservationists, compiled to mark the centenary of the founding of the U.S. National Park Service (NPS) in 1916, but looking forward as well as reflecting on the past.

It has its origins in a "summit" held at the University of California Berkeley in March 2015, organized in partnership with the National Geographic Society and the NPS with the challenging title "Science for Parks, Parks for Science: the next century". Berkeley was a particularly pertinent venue as members of the university played key roles in the establishment of the NPS whose campaigning for conservation can be traced back to the last decades of the nineteenth century. The occasion had 30 plenary speakers and discussants, including such charismatic and influential biologists as Edward Wilson and Jane Lubchenco, some 200 other oral and poster presentations, and an audience of over 550 (and over another 1000 watching the occasion live-streamed). A particular feature was bringing together people with different perceptions, including users and those affected by the parks.

The work is organized into four main sections: Mission and relevance of National Parks; Stewardship of Parks in a changing world; Engaging people in Parks; and Future of science, conservation, and Parks. While the focus is naturally the USA, there is much of wider relevance here. Wilson's opening chapter (pp. 1-16) is characteristically astute and challenging, pointing out where we are in relation to extinction rates and climate change, supplemented by a transcript of the following discussion in which further pointers are made; these few pages are well-worth commending to anyone that wants a frank account of the current rather depressing world view, but sadly they will probably be missed by the politicians that need them most.

The contributions in the four sections are very wide ranging, and include world overviews of the extent of protected areas on land and in the oceans as well as issues in the American Parks. There are chapters on the challenges posed by climate change, air pollution, invasive species, and much on how best to engage the public-including involvement in citizen science projects not least of which is the bioblitz. I was also interested to learn that the Great Smoky Mountains ATBI (All Taxa Biodiversity Inventory) had reached 18,545 species, including 951 new to science.

In addition to the formal presentations, some particularly insightful and sometimes entertaining remarks are recorded in reports of "moderated discussions". I also enjoyed the final historical Appendix on both the origin of the parks system and the key role of the University of Berkeley faculty in making this a reality, which includes photographs of many of the key players. 


\section{This land is your land: the story of field biology in America Michael J. Lannoo}

University of Chicago Press, Chicago, USA, 2018, xiv + 305 pp., illustr., ISBN 978-0226-35847-5 (hbk), 978-0-226-58089-0 (pbk), 978-0-226-35850-5 (ebk), Price: US\$ 30 (pbk).

Michael Lannoo already proved himself as a careful investigator of historical aspects of the development of awareness of the importance of field biology in Leopold's Shack and Ricketts's Lab: the emergence of environmentalism (2010, University of California Press; see BIOC 20: 1142-1143, 2011). He now builds on that in broadening it to cover the whole of field biology in the USA in this new work.

It was not a simple task to see how best to approach such a work, but his organization through contributions and approaches that successively build upon or grow from each other works well. He deals in sequence from the founders (explorers and settlers), through natural historians, ecologists, wildlife biologists, conservation biologists, and finally to restoration biologists. A truly extraordinary amount of material has been sieved through to put this work together, from institutional archives a well as published works. Sources are meticulously identified with notes occupying no less than 33 pages, and then 12 pages of references cited. There are numerous quotations from original sources, and his detective work has managed to reveal some truly remarkable photographs, not least Asa Gray with Joseph Hooker from Kew and others on a collecting trip in the Rocky Mountains in 1877. Key institutions which started new directions or spawned other researchers receive special attention, such as the Chicago school of plant ecologists. He also does not shirk from highlighting issues within organizations that have had to undergo transitions to adapt to a changing political environment, including the Bureau of Biological Survey and US Fish and Wildlife Service.

The focus throughout is on those involved with plants and vertebrates, which is one I can understand as it would have been an almost impossible task to cover all specialisms including the numerous entomologists and mycologists. There were opportunities, however, where the breadth of some could be stressed, for example F.E. Clement's seminal works with C.L. Shear on fungi. Also, there are many mentions of Harvard University and its museums, but not the far-sighted and influential Cryptogamic Herbarium founded with a bequest by W.G. Farlow in 1919. I was also surprised not to see the scholarly account of early North American botany by R.H. Petersen (2001, New World Botany: Columbus to Darwin, Ruggell, A.R.G. Ganter Verlag) referenced.

The Preamble explains that a major motivation of this book was to rekindle interest in field biology at a time when the numbers of students and researchers visiting field stations is reported to have dropped by around $40 \%$ over the last decade - as research moved from the field to the laboratory and the hands of modellers, which he clearly deplores. With so much to yet to be discovered even in relatively well-known regions such as North America, let alone the tropics, it is to be hoped that this helps address this unfortunate situation.

There is much to reflect on and enjoy here, and I found the style made it most readable. Better quality reproduction of the old half-tone photographs would, however, have been an enhancement, and it was a pleasure to see such a detailed index provided. 


\section{Moral entanglements: conserving birds in Britain and Germany Stefan Bargheer}

University of Chicago Press, Chicago, USA, 2018, xiii + 326 pp., illustr., ISBN 978-0226-37663-9 (hbk), 978-0-622-54382-6 (pbk), 978-0-622-54396-3 (ebk), Price: US\$ 105 (hbk), 35 (pbk), 10-35 (ebk).

This is both an in-depth history of ornithological studies in Germany and the UK, and a comparison of the different routes taken founded in how birds were perceived. In the UK the interest emerged from bird-watching as a leisure activity whereas in Germany they were seen as food or a part of work and protected as economic tools of especial value in the control of agricultural pests. It was, however, those that initially killed and utilized birds that were the first to take steps to protect them. In making the comparisons, he focusses on two highly successful organizations, what is now known as the Naturschutzbund (NABU) and the Royal Society for the Protection of Birds (RSPB); by 2010 these had memberships of 445,000 and 1,076,112 respectively. In 2007, there were 2,810 birdwatchers contributing annually to data collection in Britain compared with around just 1000 in Germany.

This is, however, far more than an historical comparison as the author develops a "Pragmatist theory of morality" and how nature is valued - the value attributed to birds derives from their relational position within a set of practices and institutions as social forms. This contrasts with their view as a projection of human relationships, with society primary and nature secondary. He contrasts the valuation of birds as toys vs. as tools. "Toys" include twitching (checking off species seen over time, usually whole-life lists) and birding (bird watching to see what chances to be around at a particular point in time). That the number of bird species is relatively modest compared with many other groups of organisms, with 552 in the UK and 462 in Germany, making personal life-lists potentially achievable.

Birds also became attractive as collectables, especially after the use of arsenic soap to protect specimens for museums was invented around 1755, and key publications describing and illustrating them are introduced and placed in context. Interest received a major stimulus from photography, and then the use of bird-feeders and nesting boxes started to take off-not only for the pleasure of seeing them but in Germany to encourage breeding in order increase their effectiveness in pest control. The production of field guides, checklists, and citizen-oriented magazines (especially British Birds) from the early decades of the twentieth century was a major fillip towards the development of societies and then a concern for their protection. Indeed, the RSPB was initially primarily concerned with bird welfare until it was re-focussed as a bird-watching organization mainly as a result of the efforts of J.S. Huxley in the 1930s. It was, however, after the impact of pesticides on birds hit public awareness in the 1960s that the RSPB membership started to rocket; that had little effect in NABU membership which did not show a steep rise until the late 1990s. He also documents the change in policy from an emphasis on feeding and nest boxes to acquiring and managing nature reserves. In the case of the German ornithologists, they moved from trapping themselves to making raids into Belgium to destroy traps.

As global concerns for biodiversity increased, a Birds Directive from the European Commission was issued in 1979, and BirdLife International came into being in 1994 and started to work closely with the World Conservation Monitoring Centre in Cambridge and produce the Red List for birds for IUCN. It is viewed as becoming so influential because it is an amalgamation of around 114 national ornithological organizations. 
The author has based this work not only on published sources, but has enhanced these by interviews with 68 people, including some of the most influential in conservation generally as a well as bird conservation, amongst those known to me are Charles Hussey, John Lawton, Robert May (recently deceased), John Sheail, Toy Soper, and Barbara Young. Quotes from some of these are included, and these add considerably to the value of the book as an historical record.

The concluding chapter focusses on morality and its study, and the author notes that environmental ethics is not an area those involved in bird conservation write or talk about. He sees a need for moral discourse addressing questions of how we should behave and what actions should be praised, and which should be admonished. He does not consider there is a spirit of environmentalism, a green collective consciousness, or a conservationist creed underlying how attitudes to birds have changed. These issues, and his pragmatic theory of morality, will make this work important for all involved in considerations of the ethical dimensions of conservation of any group of organisms, and not only birds. It merits a careful and reflective read.

\section{The Ark and beyond: the evolution of $z 00$ and aquarium conservation Edited by Ben A. Minteer, Jane Maienschein, and James P. Collins}

University of Chicago Press, Chicago, USA, 2018, xiv + 454 pp., illustr., ISBN 978-0226-53832-7 (hbk), 978-0-622-53846-4 (pbk), 978-0-226-53863-1 (ebk), Price: US\$ 135 (hbk), 45 (pbk), 10-45 (ebk).

Aquaria and zoos are sometimes a cause of concern for those anxious about animal welfare, but now they are making an increasingly important contribution to the survival of endangered species - as well as having an educational function. This book considers the history of the institutions, animal welfare, critical role in re-introduction programmes, how their practices and policies are evolving, and further their ethics and visions for the future. Income from visitors has a wider value, as many fund conservation projects; according to the Association of Zoos and Aquariums (AZA) its accredited zoos and aquaria fund over 2500 conservation projects in more than 100 countries, collectively spending on average US\$ 160 million annually on them.

This survey has an impressive 48 contributors, mainly from the USA, and has 30 chapters organized into six sections. The emphasis is consequently on institutions in the USA, but experience from many others and instances of collaboration with ones in lessdevelop countries are included. Examples are given of the rise of zoo and aquarium conservation in the USA, with in-depth case studies, including their role in saving animals from extinction. Six chapters examine issues of animal welfare, wellness, and connections with visitors-including ethical considerations and the need to balance recreation and conservation. The particular role of these institutions in conserving small populations are highlighted, including rescuing the many frog species now threatened with global extinction.

Examples are also given of conflicts between visitor attractions and animal welfare, including that resulting in the zoo at Yosemite National Park being closed in 1933. The aspirations of architectural designers have also caused issues in some cases, most notably in the proposal for the massive "Zootopia" in Denmark proposed by iconoclastic architect Bjarke Ingels and his company which would have been largely wall and cage free with many roaming free in multispecies habitats; this was criticized for presenting a contrived vision of nature but also supported by others as seeking to find a way for humans and other animals to co-inhabit. 
The whole is well-illustrated and extensively referenced, but sadly the quality of reproduction of many of the half-tones is disappointing. There is, however, much to ponder here for all concerned with or questioning the roles of zoos and aquaria in conservation today. It gave me a better understanding of their achievements and also an appreciation by the zoo and aquarium community of the issues they need to address.

\section{Why study biology by the sea?}

\section{Edited by Karl S. Matlin, Jane Maienschein, and Rachel A. Ankeny}

University of Chicago Press, Chicago, USA, 2020, x + 355 pp., illustr., ISBN 978-0-22667276-2 (hbk), 978-0-622-67293-9 (pbk), 978-0-226-67309-7 (ebk), Price: US\$ 135 (hbk), 45 (pbk), 10-45 (ebk).

Many will be surprised by what lies behind this title. The focus is not so much about the scientific challenges and what they might reveal about marine and global processes, but on the history and achievements of particular key marine biological stations. There are contributions on the Woods Hole Marine Biological Laboratory (USA), the Stazione Zoologica di Napoli (Italy), Amoy University Marine Biological Laboratory (China), and Misaki Marine Biological Station (Japan). Detailed historical accounts are presented of their foundation and development, including citations from key documents and biographical notes and portraits of many of the key players. In each case, key achievements are also summarized. It is unclear how the selection of stations to treat in depth was made, and I feel it is unfortunate that there are no contributions concerning two of the oldest marine biological stations, those based in Roscoff (France) and Plymouth (UK), which were founded around the same time as that in Naples in the 1870s-1880s.

A series of case studies of contributions to marine biology made from marine biological stations follows. Amongst these, the two I suspect would be of the greatest interest to biodiversity and conservation scientists are descriptions of new and unusual organisms from the Naples station, investigating the cause of declines in coral reefs and the role of infections. A final chapter looks to the future, stressing their contribution as a source of model organisms, and little understood symbioses, but especially the potential if "hundreds of carefully selected species were to be subjected to rigorous molecular, genetic, and cellular interrogation" (p. 333).

It is to be hoped that the system of marine biological stations continues to be maintained and strengthened despite the competitive funding environment many now have to operate in. This is especially so as we are now only starting to get a glimpse into the immense variety of undescribed microbial life in the oceans, its complexity, its interactions, and role in global geochemical cycles.

\section{Climate change and palaeoecology}

\section{Foundations of palaeoecology: classic papers with commentaries}

\section{Edited by S. Kathleen Lyons, Anna K. Behrensmeyer, and Peter J. Wagner}

University of Chicago Press, USA, 2019, xiv + 770 pp, illustr., ISBN 978-0-226-61817-3 (hbk), 978-0-226-61820-3 (pbk), 978-0-226-61834-0 (ebk), Price: US\$ 150 (hbk), 60 (pbk), 10-60 (ebk).

It has been many years since I saw such a collection of facsimile reproductions of original papers. The genre was particular popular in the 1970s and early 1980s, when physical copies of papers had to be searched out in libraries or ordered by surface mail. With so much now available online, the demand has naturally decreased, but there can be much 
value added by commentaries placing works in context, which is what the editors have achieved here.

Forty-four articles are presented here, organized into six categories: Community and ecosytem dynamics; Community reconstruction; Diversity dynamics; Paleoenvironmental reconstruction; Species interaction; and Taphonomy. The papers included were first published in the years 1924-1999, and each is introduced by a commentary by a researcher active in the particular topic area which places its importance in context. The quality of the facsimiles varies, as most have had to be reduced from the original journal page size to that of the book, with a consequent loss of sharpness; further, all figures are reproduced as halftones even if originally printed in colour.

The selection is necessarily eclectic, and majors on palaeoecological and evolutionary changes through geological time rather than on the Quaternary-the period which would have been of most value to those involved in conservation biology and climate change research. There is one paper on palynology of lake sediments from 1969, but not a pioneering one, and none of the classic papers on those from peat deposits that started in the first decades of the last century and have proved so illuminating (see also Dietl \& Flessa, eds, 2018, Conservation Paleobiology: science and practice, reviewed below). On the other hand there are some gems that I had not expected and which I had never seen in the original, most notably Van Valen's Red Queen hypothesis from 1973 for which he founded a new journal of his own to get published!

This collection will, however, be great for palaeobiology students to dip into to broaden their insights into the foundations of knowledge that they might otherwise just take for granted.

\section{Conservation paleobiology: science and practice Gregory P. Dietl and Karl W. Flessa (eds)}

University of Chicago Press, Chicago, USA, 2018, xi + 316 pp., ISBN 978-0-226-506722, Price: US\$40.

In a foreword to this volume, Thomas Lovejoy reminds us that most people in the policy arena do not have the technical background to understand the long-term interrelationships of the Earth's combined biological and physical system. This is topically highlighted by the deliberations of the Intergovernmental Panel on Climate Change (IPCC), and if scientists don't communicate clearly, how can global change be taken as seriously as it merits? This book is an expanded reprint of the proceedings of a Geological Society of America short course which took place in 2009. The text of the original proceedings remains unchanged, but their collation is augmented with a new introduction, brief perspective pieces for the three sections (each a little over one page in length), a roundtable discussion by five conservation biologists (12 pages) and a two-page epilogue. Does this work? In part.

The introduction is a slim affair (less than two pages of text) and tells us that "what is new about conservation paleobiology is that it provides a sense of community for palaeontologists of all sorts who share a desire to play an active role in doing something about today's biodiversity crisis." This is hardly agenda-setting, but is in keeping with the intention of offering primers on conservation issues arising from geohistorical records.

The section perspectives are basically a listing of the chapters with minimal comment. Over half the book is given over to Section 1 on conservation palaeobiology in near time. This focuses upon Quaternary age approaches and examples, where there are ready connections with present-day biotic patterns and processes given the relatively familiar spatial configurations of land and sea and the demonstrable role of anthropogenic influences upon 
landscapes and climate. Thus studies of mollusca, (in)vertebrates, pollen, limnology, isotope ecology and macroecology benefit from the availability of numerous detailed records which have produced convincing proxies for environmental change and provide the data for predictive modelling. Section 2 on conservation biology in deep time can play with the entirety of the fossil record which may embrace evolutionary processes. Although there are obvious overlaps between the approaches of the two sections, the chapters within the second are perhaps more reflective in their embrace of macroscale and longevity as exemplified by global warming, ocean acidification, global ecosystems, along with considerations of inference, prediction, model building and the reciprocal illumination of evolutionary and conservation biologies.

Section 3 is concerned with conservation palaeobiology in practice. It is somewhat anomalous in relation to the foregoing. Thus, chapter 14 is an account of editor Karl Flessa's scientific journey from taphonomist to conservation palaeobiologist. This contains some useful reminders of the connections between the translation of palaeobiological knowledge into conservation action (or lack of it). For instance, taking no action ("neutrality") if you believe that society is responsible for environmental degradation "means that you have accepted the outcome"; interesting, but one wonders what the philosophers would make of this? Readers are urged to go to the meetings of conservationists and should not expect them to attend scientific symposia; the obligation to be honest brokers allows us to work with advocacy groups of all persuasions.

The roundtable conversation emphasizes the personal, practical and institutional factors affecting the application of conservation palaeobiology. This new material contains some interesting nuggets. Thus Mark Brenner prefers to speak of 'management' as opposed to 'conservation' per se; John Pandolfi thinks that conservation agencies are often surprised at the heavyweight nature of scientific research—individuals "will almost shake their head in resigned disbelief that they really do have to include the past in their work"; through to mundane comments on the extent to which work with NGOs has shaped research directions, is incorporated in teaching, or the frequency of interaction with agency personnel.

The epilogue looks to the future for a geohistorical perspective to conservation in the Anthropocene. It mentions (the brevity of treatment does not allow of debate) the challenges for traditional approaches to conservation which are reactive and focused upon preservation. In contrast, 'Anthropocene-aware conservation' is about working in situations of anthropogenic change. Should elephants or lions be moved to North America? Should synthetic biology be used via ancient DNA to combine rewilding with "de-extinction" (e.g. genetically modified elephants, with woolly mammoth DNA, to the Arctic)? Should there be a repopulation of defunct niches with species from elsewhere? Conservation biology could inform such decisions and the editors "judge that the greatest value of geohistorical information to conservation lies in providing contextual information for the design of management responses and anticipation of future changes, with particular concern for the maintenance of ecosystem functions and services." Furthermore, "the overarching lesson to take away from these pages is that geohistorical records testify to a variety of past species, conditions, and signals of change". These two anodyne sentences belie the often stimulating content of the individual chapters. It is a shame that the contributing authors seem not to have been given the opportunity to update their contributions from 2009. Likewise, the editors might have been advised to expand considerably on the additional materials, although they are to be thanked for ensuring that otherwise unobtainable output is made more readily available.

Kevin J Edwards

(k.edwards@abd.ac.uk) 


\section{Ground truth: a guide to tracking climate change at home Mark L. Hineline}

University of Chicago Press, Chicago, USA, xiii +229 pp., illustr., Price: US\$ 20.00 orf 15.00, ISBN 978-0-226-34813-1 (pbk).

This book encourages people to observe for themselves possible signs of climate change through phenology, the study of the timing of biological cycles, such as annual events in the natural world; for example when particular plants flower, the run in sugar maples starts, or migrating birds, mayflies or mushrooms appear. The author, who lives in Maine and teachers the history, philosophy and sociology of science at Lyman Briggs College of Michigan State University, advocates regular observations in ones' own "dooryard"-the area where you frequent around your home, but not just on your own property. This is most commendable, and anything that encourages people to take more interest in the biodiversity around then is to be applauded.

The author was clearly stimulated by Bill McKibben's End of Nature (1989), was a real wake-up call; I have a copy on my shelves and it is always worth a re-read. This is not intended as a self-contained practical guide as to what the citizen scientist should record and how, but has numerous historical references to seasonal observations made by scientists and naturalists from classical and seventeenth century observers to more recent luminaries and campaigners such as Thoreau, Carsson, and Leopold. For the just what to do, and how their observations might help, readers are directed to various web-based initiatives such as FrogWatch or Budburst. I do, however, wonder how many readers would take such extra steps, and would have liked to see direct references to journal papers and guides. While I can appreciate that the author is not primarily a biologist, I was sad to see mushroom appearance implied to possibly be linked to host plant cycles, while that may be true for some, in reality many are saprobes living on dead wood and leaves. I also wonder whether some mention might have been made to looking for the appearance of species extending or contracting their ranges, something now evident for some lichen fungi in Europe.

\section{Global health and sustainability}

\section{Planetary health: protecting nature to protect ourselves Edited by Samuel Myers and Howard Frumkin}

Island Press, Washington, USA, 2020, 536 pp., 100 figs, ISBN 978-1-61091-966-1, Price: 39.00 .

It could be said that this book is published too early or published too late. I notice that the editors have included a forward and an afterword that had been put in there after the COVID-19 crisis started; in part that is because this book is really about the relationship between people and nature and the importance of that relationship for human health and wellbeing. This has been starkly brought to the front of our consciousness by the COVID19 pandemic. The disease is theorised to have started in bats and have transferred to humans in a wet meat market, possibly through a secondary host. With the lockdown in many countries people are more aware and even craving of experiences in nature for both their physical and mental health.

In large part this book could be an "I told you so" because it is a comprehensive review across the recently emerged research endeavour of planetary health, the intersection between ecology/environmental sciences and the health sciences. Planetary Health is 
highly interdisciplinary, predicated as it is on the basis that human health and the health of the planet are inextricably linked. I would recommend biodiversity and conservation scientists to read this book because it shows how our understanding of the complexities and interaction of the natural world have direct relevance to managing many existing and emerging human diseases. I was particularly tickled by the reference to the American opossums being such ardent groomers that they are "incompetent" [strange word] hosts of the ticks that spread Lyme disease. Competent hosts are white-footed mice whose populations boom in highly fragmented and low diversity landscapes typical of the eastern seaboard of the USA.

The book is broken up into a number of sections in four parts-after an initial foundations section which is useful given the recent history of this new interdisciplinary approach we then move onto the health of the populations, pivoting from threat to opportunity and finally saving ourselves saving our planet. Key here is that "It is now evident that environmental policy and management must be considered an integral part of health policy and management". Music to my ears.

The editors have done an excellent job in drawing together some deep and critical thinkers about planetary health, and so this will be a useful introductory textbook in undergraduate classes in ecology or environmental sciences as well as the health sciences. I would also like to see Planetary Health used as a primer for those from industry or policy involved in the challenges of how we protect our planet to ensure that it meets the health aspirations of future generations.

I am already looking out for the 2nd edition; COVID-19 is bound to make it an extremely interesting read!

Iain Gordon

(Iain.Gordon@anu.edu.au)

\section{Renewable energy and wildlife conservation}

\section{Edited by Christopher E. Moorman, Steven M. Grodsky, and Susan P. Rupp}

John Hopkins University Press, Baltimore, USA, 2019, viii +267 pp., i55 figs, ISBN 978-1-4214-3272-4, Price £ 55.50.

This book, published in association with The Wildlife Society, is particularly timely as nations aim to reduce dependency on fossil fuels and develop long-term policies to realize that vision. It is especially pertinent to me as an elected local district Councillor in Surrey (UK) as we consider what policies we should adopt in response to the "climate emergency". Novel technologies are being developed apace, and we also must be aware of any possible adverse effects on wildlife. This is what this book endeavours to do by bringing together 14 specialists in the US, mainly from universities, but including ones from consultancies, commercial, and conservation organisations.

The book starts with a lucid global overview by the editors, which has some key graphs dramatically illustrating world population growth and trends in the use of renewables to 2050, and also a ranking of countries by their total $\mathrm{CO}_{2}$ emissions. Contributions are then organized into four groups focussing on bioenergy, wind energy, solar and waterpower, and the future; all considering the impacts on wildlife and most reporting actual studies and meta-analyses.

The bioenergy section first considers short-rotation woody crops planted for that purpose and which provide biodiversity gain where one study looked at Pinus palustris sites across three states and detected $>6,600$ bird detections involving 81 species, four of which 
were of conservation concern. Biomass harvesting involving clear-cutting, can sometimes be less dramatic to vertebrates than might be expected due to downed woody material left behind, but removal of harvest residues adversely affected a wide range of invertebrates but also stimulated the invasive alien red fire ants (Solenopsis invicta); thinning, however, has fewer effects and some canopy opening can favour species of concern such as the endemic gopher tortoise (Gophursus polyphemus). Annual crop production for biofuels has expanded dramatically in the US during the last 15 years, especially of soybean, expanding into former grasslands and so negatively impacting all the associated wildlife, including the migratory monarch butterfly (Danaus plexippus); this trend has, however, to some extent been ameliorated by a Conservation Reserve Program that started in 1985 paying farmers to take land out of crop production. Six best management practices for biofuel crop farms are commended (p. 58). Cellulosic bioenergy production from non-food crops with high biomass production, using a considerable range of plants, particularly grasses and including giant miscanthus grass (Miscanthus $\times$ giganteus), though production levels achieved with that species appear less than those obtained in Europe; forest residues are also being used as a source of biofuels. A new and intriguing dimension is the development of cellulosic nanofibre materials for 3-D printing. Some attention is given to biogas derived from animal wastes and silage, involving anaerobic digestion systems.

Wind energy, which has risen globally from under $50 \mathrm{~K}$ Megawatts in 2004 to almost 500 by 2016, and has been a major source of concern to conservation scientists, as a consequence of bird and bat kills, each of which have a chapter. Collision rates reported can be dramatic, with 134,000-230,000 per year in Canada and the USA, but the longstanding debate as to how these compare with strikes with buildings and other tall structures remains unclear. Some notable rare and endangered species are killed, including western burrowing owl (Athene cunicularia hypugaea) and white-tailed eagles (Haliaeetus albicilla). Data from off-shore wind farms is difficult to obtain for comparisons with landbased farms as carcasses sink or are removed by currents. The European Community has mandatory directives, but in the US there are only voluntary guidelines; mitigation involves careful siting, shutting at peak migration times, light colours, flashing lights, and so-called compensatory habitat provision. The situation with bats is largely parallel, avoiding siting near roosts or hibernacula, and stopping or slowing when bats are active; ultrasonic deterrents are also being experimented with. There are issues over monitoring, and the use of two estimators is recommended. There are especial concerns over bats from non-local sources and the proportion of females killed, but understanding "is hindered by a lack of robust data". One chapter considers organisms other than birds and bats; there are data on ungulates and bumble bees particularly, and some parallels may exist for caribou from reindeer data from Europe. Habitat loss, especially of migratory routes are a particular concern as are ground-nesting species such as prairie grouse species (Tympanuchus spp.) and greater sage grouse (Centrocercus minimus). Information on insects is meagre, the rusty patched bumblebee (Bombus affinis) being an exception. No data are provided on effects on the soil invertebrate communities where vibrations are a potential cause of concern.

In the case of solar farms, siting is a major concern, but previously contaminated or degraded land can be used. Vegetation and other wildlife can be enhanced between panels, including butterflies and bees. At the 1,896 hectare California Valley Solar Ranch, seven plants of conservation concern and three federal or state-listed mammals are established, including the giant kangaroo rat (Dipodomys ingens), and there were 55 fox dens under the panels by the San Jocquin kit fox (Vulpes macrotis mutica) in 2017. Provided attention is given to siting and fencing type, solar farms can clearly enhance biodiversity and provide 
conservation gains. Hydroelectric power effects of most concern after dams are built relate to flow release resulting in rapid changes in water levels that can adversely affect muddwelling wildlife in the dam area and also downstream, and especially by providing obstacles to fish migration. Eel ladders and routes for fish can, however, be incorporated into the construction. Freshwater mussels are a particular concern, with 32 of 69 species not being seen post-construction in one case in Alabama. Turbines within pipes, however, appear to be essentially benign. The conservation impacts of marine hydroelectric installations are poorly known, though toxic bloom formation can be an issue in tidal barrages. They can be a cause of cable entanglements, and prevent fish and marine mammals reaching breeding grounds.

The impacts of changing policy directives on renewable energy initiatives are addressed in the penultimate chapter; tax credits in the US led to a surge in wind farm construction up to 2012 , but it then fell by $96 \%$ in 2013 when these ceased. There is a recognition that guidelines need to be replaced by regulations. The final contribution looks to the future, and has the aspiration that "the book provides a foundation on which to build " (p. 254) and a "creative springboard for building renewable energy ecology to conserve wildlife into the future" (p. 259). The lessons and guidelines presented here, showing risks but also actions for mitigation or even enhancement for wildlife, although from a North American perspective, are ones from which all concerned with developing renewable energy policies can benefit. I cannot recommend it more highly.

\section{Ecology}

\section{Extreme conservation: life at the edge of the world Joel Berger}

University of Chicago Press, Chicago, USA, 2018, xxi + 376 pp., illustr. (some col.), ISBN 978-0-226-36626-5 (hbk), 978-0-226-36643-2 (ebk), Price: US\$ 30 (hbk), 30 (ebk).

This is very much a book written for the population at large, with a racy style capturing the rigours and amazing experiences of the author as he travelled in from the Himalayas and the Tibetan plateau into the arctic circle and the frozen Chukchi Sea between Siberia and Alaska.

The primary focus was to discover what the situation was with the critically endangered saiaga antelope (Saiga tatarica) that has declined catastrophically. The species was formerly widespread from the eastern European mountains through the tundra and plateaux eastwards and northwards to well into the arctic, but in 2015 the populations fell by around $40 \%$; over 100,000 died from a mysterious disease. But this is much more than a technical assessment as the book is full of observations of other striking and charismatic animals encountered and how the local populations regard and utilize them. These include grizzly bears, polar bears, yaks, wolves, chirus antelopes, and particularly herds of muskoxen.

The book is full, however, of numerous other insights into how local peoples make a living in these extreme conditions, including for example the collection of the caterpillar fungus Ophiocordyceps sinensis, locally called "yartsa", which reached a staggering US\$ 50,000 per pound in 2012; in 2009 seven Nepalese collectors are reported as being murdered by farmers as the stakes were so high. There is also much on how outside organizations and consumers in the west positively or negatively affect conservation in the region, and historical changes in animal populations; many comparisons and tid-bits are worked in including extreme region as far away and different as the Namibian desert. 
I found it full of perceptive insights and a gripping read. At such a modest price, it is certainly something that would be a great Christmas gift for the armchair naturalist which you could be confident would be enjoyed.

\section{Bombs away: militarization, conservation, and ecological restoration David G. Havlick}

University of Chicago Press, Chicago, USA, 2018, 204 pp., illustr., ISBN 978-0-22654754-1 (hbk), 978-0-226-54768-8 (ebk), Price: US\$ 35 (hbk), 10-35 (ebk).

The often vast areas formerly used by the military for training or demilitarized and other zones left after conflicts provide new opportunities for wildlife to expand into. In the USA some 20 National Wildlife Refuges have been created on former military bases and even a disused chemical weapons factory. There is an inevitable debate as to whether these should be left for opportunistic colonization or be subject of carefully planned restoration but, somewhat frustratingly for the conservationist, little detail is presented as to what has been done or is planned in this respect at particular sites. The author was enabled to visit and photograph a huge variety of such sites across the world with the help of a National Science Foundation multi-year award. These included ones of the former iron curtain (now a European Union-sponsored green-belt Iron Curtain Trail), the demilitarized zone across the Korean Peninsula, atomic bomb testing sites in the Indian Ocean, Bikini Atoll in the Pacific Ocean where the USA detonated its largest nuclear bomb in 1954, Hiroshima itself, and the classic Orford Ness site in south-east England formerly belonging to the UK Atomic Weapons Research Establishment and which is now a National Nature Reserve.

Perhaps the main value of this book for conservationist will be able to show it to those concerned with finding new uses for former military sites to demonstrate what other authorities have and are doing over their futures.

\section{Phylogenetic ecology: a history, critique and remodelling Nathan G. Swenson}

University of Chicago Press, Chicago, USA, 2019, xi + 216 pp., illustr., ISBN 978-0-22667147-5 (hbk), 978-0-226-67150-5 (pbk), 978-0-226-67164-2 (ebk), Price: US\$ 120 (hbk), 40 (pbk), 10-40 (ebk).

The concept of being able to characterize and compare the diversity of different sites using numerical methods is far from new, but to what extent can the major progress made in understanding phylogenetics of the last 30 years contribute to fresh objective assessments?

The first third of the book is in essence an introduction to phylogenetics that those not already familiar with what is behind their use in systematic an evolutionary studies may find of value. But how can phylogenetic data be used in practice to characterize and provide a tangible measure of value with which to compare and assess the relative conservation importance of particular communities? This is an issue for which there is no easy answer as there is as yet no site on Earth that has anything approaching a complete organismal inventory, even of described species present. In the penultimate chapter, the author looks to providing trees taking in others derived from different groups of organisms; trees of trees. This is fine as an aspiration, but one that is unlikely to be realizable for many decades to come; indeed, the author speaks of producing a "road map" for the future.

Where the approach can be of value is when communities are compared using data from phylogenetically well-studied groups of organisms such as vertebrates or plants. This may help inform which communities merit prioritization on the basis of the phylogenetic 
diversity of, for example, a particular group of organisms. These are topics addressed in some of the contributions to a book which was apparently overlooked by the author which was published in 2016 (Pellens \& Grandcolas, eds, 2016, Biodiversity Conservation and Systematics, Springer).

\section{Discoveries in the garden James Nardi}

University of Chicago Press, Chicago, USA, 2018, ix + 280 pp., 123 figs, 3 tables, ISBN 978-0-226-53166-3 (pbk), Price: US\$ 25.00.

What a delightful book! Although the focus of this book is to increase understanding of the scientific aspects of gardening, it is at the same time sure to increase awareness of fundamental scientific processes related to the conservation of biodiversity in natural environments of both enquiring adjusts and questioning children. It challenges readers to see what can be learnt from gardens.

After a brief introduction to what plants are from the ultrastructural level to interactions with animals, chapters challenge the reader to observe and hypothesize from what can be seen at a variety of levels from: seeds; buds and stems, stem cells and meristems; the underground world; the journey from flower to fruit and seed; energy from the sun and nutrients from the soil; movements of vines and tendrils, leaves and flowers; wisdom of the weeds; plant colours; plant odours and oils; and fellow gardeners-other creatures that share our gardens.

It is packed with superb illustrations, and does not shirk from magnified sections and chemical formulas so all explanations have the scientific bases laid bare. Some simple experiments are also to be found, such as how to demonstrate osmosis. Especially pleasing to me was to see much on the interaction between different organisms in the garden, above and below the surface, from bacteria, insects, and mycorrhizal and other fungi to pollinators and even cats. There are also historical tid-bits scattered throughout, explanations of terms, a very full glossary, and a particularly detailed index.

The author, a biologist at the University of Illinois at Urbana-Champaign, is to be congratulated on producing a book that is at the same time engaging and educational. It challenges gardeners and those visiting gardens to be become more aware of the complexities of plants and their interactions within their gardens-and will by extrapolation help make them more aware of those in the wider environment.

\section{Primer of ecological restoration Karen D. Holl}

Island Press, Washington, DC, 2020, 224 pp., 19 figs (2 photos), ISBN:978-1-61091-972-2 (pbk), 978-1-61091-973-9 (ebk), Price: US\$ 35.00 (pbk), 34.99 (e-bk).

I sit here with the bush fires blazing to the south and southwest of where I live in Australia. Thus far, and we are still early in the fire season, over $10 \mathrm{M}$ hectares of land is affected, a land area the size of England. Obviously, the immediate actions are focused on saving lives and property, but the discussions about the causes, and the actions to prevent future catastrophic fires, will play out across the political divides for some time to come. However, now is the time to put in place action plans to help the damaged ecosystems to recover, adapt and build their inherent resilience to the likely increasing frequency of climate induced threats, such as fire. Also, closer to home were the widespread bleaching events on the Great Barrier Reef (and elsewhere) in 2016 and 2017. We can sit back and 
wait for the Reef to "recover" or we can actively restore its structure, function and ability to adapt in the face of climate change. These examples highlight the need for ecologists to engage effectively in management actions to restore degraded ecosystems, and for managers to gain an insight of how ecology can be used to more effectively achieve their goals. With Karen Holl's Primer of Ecological Restoration we have a fantastic starting point for both audiences. Karen has many years of experience of practical restoration ecology in projects across the world. She has used this experience in her courses at the University of California for years. In the Primer Karen clearly lays out the steps necessary to effect better restoration projects. The Chapters are short, full of useful information, with valuable Recommended Reading at the end of each Chapter. Alongside the book there is a website with case studies, videos and other useful resources (islandpress.org/restoration-primer). Karen makes a very clear case for the needs for monitoring and the engagement of science in the adaptive management cycle of learning by doing. This is fundamental to a long-term role of restoration beyond what can appear to be green washing. I have no doubt that the Primer will be used as the foundation for academic and professional courses on ecological restoration leading to better engagement between ecologists and practitioners in group projects. Getting back to the bush fires, images of suffering koalas have prompted the Australian Government to announce as I write A\$50 M for wildlife affected by the fire, including $\mathrm{A} \$ 3 \mathrm{M}$ for restoration projects. By my rough calculation this will restore about 1500 ha of forest (estimated at A $\$ 2000 /$ ha). A drop in the ocean so to speak.

Iain Gordon

(Iain.Gordon@anu.edu.au)

\section{Community engagement}

\section{Community-based control of invasive species Edited by Paul Martin, Theodore Alter, Don Hine, and Tanya Howard}

CAB International, Wallingford, UK, 2019, xx + 268 pp., illustr., ISBN 978-1-78924253-9 (hbk), Price: $£ 75$.

How to tackle issues of invasive species is an increasing issue of concern worldwide, and on such a scale, that involving communities will increasingly become essential if adverse impacts are to be eliminated or at least controlled. In 2011, this need was recognized by the Invasive Animals Cooperative Research Centre (IACRC) in Australia which then established a project to address just how to pursue community engagement. This book is a report of the progress made in the first seven years of this initiative.

The book comprises 12 chapters involving 27 contributors, drawn from Australia and the USA (mainly Pennsylvania State University). While it therefore has a focus on the experience of these two countries, some of the lessons to emerge will be helpful globally. The first chapters describe the governance structures and institutions under which invasive species managers work - and how institutions have to adapt to changing situations and policies; they need to be adaptive and learning organizations and some examples of how some groups have managed to embed this into their work are provided. A series of chapters then looks at issues of shared responsibility and the need to adapt expert/citizen relationships and the changing role of leadership. The book then proceeds to see what can be learnt from experiences in behavioural sciences to ensure more effective social engagement, and the need for carefully crafted communication to different 'segment 
groups' in society. Care is also need dealing with mass-media which can be especially important in influencing peoples' views.

The final chapter looks at how the outcomes from the programme can be used to increase the effectiveness of invasive species management. These include ones related to organizations and institutions concerned with farm weeds, and seven more general institutional problems: stakeholder incentives, limitations of government, inconsistencies, uneven accountability, communications, practical respect, and citizen limitations. Performance criteria for invasive species institutions are provided, and directions that need to be taken to increasing implement shared responsibility are identified.

This is clearly a work that will be of interest to those involved in community engagement generally, and not only for invasive species; further, an impressive list of publications and web-based resources generated from the project is provided (and extends over five pages).

This book is also published exclusively in Australia and New Zealand by CSIRO Publishing under ISBN 9781486308873 (hbk), 9781486308880 (PDFbk), and 9781486308897 (ebk).

\section{Animal behaviour}

\section{Critical terms for animal studies Edited by Lodi Gruen}

Chicago University Press, Chicago, USA, 2018, 472 pp., ISBN 978-0-226-35542-9 (pbk), Price: US\$ 32.50 .

In the introduction, the editor explains that "animal studies" is generally described as a new and emerging field for which roots have been searched for in the 1990s; the journal Society and Animals was launched in 1993. This work aims to describe the "critical terms", defined as the tools that are needed to help solve conceptual problems within "animal studies". Twenty-nine terms each have a chapter devoted to them by different authors, and the coverage may be best illustrated by listing these: abolition, activism, anthropocentrism, behaviour, biopolitics, captivity, difference, emotion, empathy, ethics, extinction, kinship, law, life, matter, mind, pain, personhood, postcolonial, rationality, representation, rights, sanctuary, sentience, socialite, species, vegan, vulnerability, and welfare. The intended audience is clearly sociologists and those concerned with animalrights rather than biologists, but it could perhaps serve as a wake-up-call to biologists as there is clearly a major group of researchers where bridges wait to be built. I actually found it quite worrying that the subject was considered to have started in the 1990s. I could find no reference to the pertinent founding behavioural studies of Julian Huxley going back to the 1920s, the key words "sociobiology" or "biophilia" (despite the extensive index), any of the numerous books by Edward Wilson, only a single passing reference to ants (p. 68), and the account of species seemed oblivious of phylogenetic species concepts-with DNA just mentioned for the separation of wild from domesticated populations. There is clearly a need for sociologists working in this area to take time out to collaborate with biologists experienced with animal behaviour in nature. 


\section{Biodiversity utilization}

\section{The ethnobotany of Eden: rethinking the jungle medicine narrative Robert A. Voeks}

University of Chicago Press, Chicago, USA, 2018, xii + 321 pp., illustr., Price: US\$ 45 or $£$ 34, ISBN 978-0-226-54771-8 (hdbk).

The belief that tropical forests are a potential source of immense wealth to be derived from yet undiscovered pharmaceutical products has been one of the arguments of conservationists, and a driving force of many governments anxious to bring in legislation to prevent outsiders capitalising on their natural resources. The dream of unrealized wealth has been a key driver in the development of the 1992 Convention on Biological Diversity, and more recently in the prohibitively restrictive Nagoya Protocol to that Convention of 2010 which is already starting to stultify biological exploration and research.

The paradigm of undiscovered and unexploited resources may seem reasonable in the light of the huge numbers of plant species to be found in tropical forests, but does it stand up to scrutiny? Here, Robert Voeks, editor of the highly respected and long-established journal Economic Botany, and a professor in the California State University Fullerton, critically examines the evidence for this almost universally held belief. He examines discoveries made and the outcomes of collaborative bioprospecting initiatives based on published work and supplemented by his own personal experience as an ethnobotanist working with indigenous peoples in countries in Africa, South America and South-East Asia. His conclusions will undoubtedly come as a shock to many conservationists and can be encapsulated in this quote: "although this compelling story helped spread the gospel of 'save the rainforest', evidence suggests that no life-saving drugs were developed, no diseases were cured, no fortunes were made, and no tropical forests were protected" (p. 19).

In his experience with local people, most plants used for medicinal purposes were weedy species of disturbed habitats around dwellings rather than in pristine forests. These were generally richer in natural products than, for example, evergreen leaves of rainforest trees, and he considers a collaborative focus on already employed plants to be the most promising approach. While noting that natural product discovery programmes have been axed by most of the larger Pharma companies, in my experience these tended to be targeted on very specify kinds of drugs they were searching for; thus there could well be valuable compounds there with unexpected attributes which have not been tested for. While the focus of the author is primarily on plants and the beneficial products found in them, in the case of fungi, many of the recent successes (including cyclosporins, pneumocandins, and statins) have actually have been from species isolated in temperate rather than tropical regions.

The conclusions of this study need to be taken note of by both conservationists and politicians, but while the author does see some evidence for regulatory bodies becoming more realistic, I fear that it will be difficult to modify the trajectory of current intergovernmental processes. 


\section{Regional works}

\section{Biodiversity of the Himalaya: Jammu and Kashmir State Edited by Ghulam Hassan Dar and Anzar A. Khuroo}

Springer Nature, Singapore [Topics in Biodiversity and Conservation vol. 18], 2020, 1096 pp., ISBN 978-981-32-9173-7, Price: € 239.19 (hbk).

The title of this book intrigued me, as a citizen of Jammu and Kashmir State and a student of botany and forest ecology. I have always been enthusiastic to know the status and magnitude of biodiversity of the state, i.e. what, where and how much biodiversity we have in the state. During the last ten years, I have always enquired if there were such a book when visiting major bookshops, unaware that one was under production.

This book provides a comprehensive account of the biodiversity of this westernmost region of the Indian Himalaya, amassing the rich information regarding the biodiversity and stressing areas that are yet unexplored. The book is expected to garner support for the conservation of marvellous biodiversity and beauty of the region. The rich biodiversity would have certainly made the Mughal emperor Jahangir call Kashmir a "paradise on Earth". The information on this biodiversity has been scattered through hundreds of journal articles, books, project reports, conference proceedings, etc.-much of which is fragmented and practically inaccessible. This book amasses this scattered rich information to provide an authoritative summary.

The idea of collecting, assembling and accumulating the information on the biodiversity was conceived by Ghulam Dar back in 2012, but progress was suspended until Anzar A. Khuroo was able to join him as co-editor. The book includes 42 mostly well-written chapters by 87 regional, national, and foreign contributors with expertise in their particular fields. These are grouped into six parts: Part I (General Introduction) contains a single chapter by the editors that provides a concise summary of the contents of the book with a brief and clear outline of all the 42 chapters; Part II has four chapters dealing with global and national perspectives of biodiversity; Part III with four presents a general account of the region and its biodiversity; Part IV has three dealing with the genetic diversity of a few plant and animal groups; Part V has 14 covering algae, fungi, lichens, macrophytes, bryophytes, pteridophytes, gymnosperms, angiosperms, medicinal and aromatic plants etc.), together with an account of poisonous plants; Part VI of ten is concerned with animal groups (ants, butterflies, flies, insect pests of medicinal and aromatic plants, beetles, fishes, amphibians, reptiles, birds and wild mammals); and Part VII has six addressing conservational aspects addressing threatened species, impacts of urbanization and climate change, current status, future challenges, the legal framework, and concerns for conservation.

The various ecosystems of the region and its rich biodiversity are facing threats, mostly anthropogenic in nature, which result in a deterioration of their ecological importance and status. These include habitat loss and/or fragmentation, mining, conversion of forests and grasslands into agricultural land, poaching for wildlife trade, a huge tourist influx, flourishing human/livestock populations, human-wildlife conflicts, overgrazing, and lack of awareness in local communities. A few natural activities, such as landslides, soil erosion, invasive alien species, and flash floods, are also important. Approaches such as habitat conservation, implementation of conservation laws, and increasing awareness of local communities are needed to ensure the long-term survival of these biodiversity rich ecosystems. 
This book is timely as it was necessary to amass the information on the rich biodiversity of the region, to fill the huge knowledge gaps, and provide a comprehensive, up-to-date and consolidated synthesis under a single cover. A vast area of the region is inaccessible and under international borders and hence remains unexplored due to which the truly comprehensive knowledge of its biodiversity is still incomplete. Areas under the control of Pakistan (Pakistan-Administered Kashmir) and China (Aksai Chin) can't be accessed by Indian researchers. However, the book presents baseline data for future biodiversity studies in the region which have a vast scope as no component of biodiversity is yet fully studied and explored, a point made at the end most chapters. Even the number of species of certain groups, such as viruses, bacteria, platyhelminthes, and nematodes reported is not known.

The price is extremely high for personal collections, but it can be an asset for educational institutes and research organizations. The inclusion of available vernacular names in the checklists would have made them more complete as these are particularly helpful for communication with non-biologists. Similarly, notes on local uses of plants would have added another valuable aspect. There is, however, some duplication of information and inconsistencies, such as the values for the area (\%) occupied by Jammu, Kashmir and Ladakh regions as $25 \%, 15 \%, 58 \%$ (Ch 6) and 19\%, 11\%, 70\% (Ch 7) respectively. There is also an inconsistency in the numbers of mammalian species mentioned in the text ( $\mathrm{p}$. 935) and presented in the checklist (pp. 936-42) in Ch 36. That same chapter (36) states in the abstract (p. 933) that "the State possesses 112 species of mammals: including 34 globally threatened with 1 Critically Endangered, 6 Endangered, 12 Vulnerable, and 8 Near Threatened species", but at p. 946 it is mentioned that "fifteen species fall under the threatened categories of CE, EN, and VU, while 12 species fall under the NT category", while in Fig. 36.1 (p. 946) only 15 species are shown as threatened (1 CE, 6 EN and 8 VU) but the number of VU (12) and NT (8) species mentioned in the text (p. 933) are switched. Apart from this oversight, the standard of editing and proofreading has been amazing.

I am sure this work will have an extended shelf life as an authoritative source of on the biodiversity of Indian Himalaya in general, and the Jammu \& Kashmir State in particular. It is rigorous enough to be used as a stand-alone reference. Charming and attractive pictures of some rare plants and animals combined with easy to read concise accounts also make the book suitable for recreational reading even for non-biologists. I hope this book will be helpful to all its potential users, including students, teachers, researchers, taxonomists, ecologists, biodiversity conservationists, and the general public. The book has found a permanent space on my office shelf and also in the reading room in my home.

Zubair A. Malik (malikmzubair081@gmail.com)

\section{Last days of the mighty Mekong Brian Eyler}

Zed Books, London, UK, 2019, 417 pp., ISBN 978-1-78360-4 (hbk), 978-1-78360-719-8 (pbk), 978-1-78360-722-8 (ebk), Price: £ 70.00 (hbk), 12.99 (pbk), 12.99 (ebk).

The $4300 \mathrm{~km}$ long Mekong river originates on the Qinghai-Tibetan plateau and runs through China, Myanmar, Laos, Thailand, Cambodia, and Vietnam, an area with a population of over 70 million people and undergoing major changes. About half of the river is in China, which has plans to improve connections through high-speed rail links and to transform the region, also building a new series of dams to harness the river's energy. 
The author, who is based in Yunnan University, describes his journey from the headwaters in China right through to the delta in southern Vietnam where it joins the sea. He has discussions along the way with people from villagers to politicians and policy makers in order to learn of what is being done by local to international groups to preserve this already pressurized, fragile, and increasingly threatened ecosystem. It is very much in the form of reporting the discussions and opinions of people he met on way, revealing their current anxieties and recollections of how things used to be. He also provides historical background on political and boundary changes and the influence or European and US powers, especially since the early decades of the twentieth century.

While there is no overview of the biodiversity, the issue of fish and the impacts of dams is the issue that features especially strongly with local peoples; the latter include cultural and ethnic groups that are themselves concerned about the survival of their traditional ways of life. It is not, however, surprising that impacts on fisheries is a recurring theme as around 700 of 1000 fish species known in the system are migratory; the fish diversity is reported to be second only to that of the Amazon. Many of the wetlands are covered by the Ramsar Convention, and the author stresses the need for international as well as local organizations to lobby the various governments involved to take actions to mitigate biodiversity loss and to increase statutory protection.

This is a travelogue with a purpose, dubbed "a moving requiem for a complex ecosystem on which millions depend" by Judith Shapiro, author of China's Environmental Challenges (2nd edn, Polity Press, Cambridge MA, 2016). The most readable style renders it readily accessible not only to environmentalists, but to the leaders and policy makers who may be in positions where they can influence the directions of future changes. It is to be hoped that the book gets into the hands of those key decision makers in all the countries along the river' length, something that would be greatly facilitated by having a Chinese translation available.

\title{
Other books received
}

\author{
Hierarchy: perspectives for ecological complexity \\ Second edition \\ T.F.H. Allen and Thomas B. Starr Chicago University Press, Chicago, USA, 2017, \\ 417 pp., ISBN 978-0-226-48968-1 (pbk), Price: US\$ 47.50.
}

\section{Thinking like a parrot: perspectives from the wild \\ Alan B. Bond and Judy Diamond}

University of Chicago Press, USA, 2019, xiii + 267 pp., illustr. (some col.), ISBN 978-0226-24878-2 (hbk), 978-0-226-24881-3 (ebk), Price: US\$ 35 (hbk), 10-35 (ebk).

\section{The peregrine returns: the art and architecture of an urban raptor recovery Mary Hennen \\ University of Chicago Press, Chicago, USA, 2017, xiii + 211 pp., 159 col. Illustr., ISBN 978-0-226-46542-5 (hdbk), Price: US\$ 25.00.}

Publisher's Note Springer Nature remains neutral with regard to jurisdictional claims in published maps and institutional affiliations. 